\title{
The Market Dynamics of Socially Embedded Trading
}

\author{
Kenneth A Frank \\ College of Education, Michigan State University \\ kenfrank@msu.edu \\ Yun-Jia Lo \\ Independent \\ loyunjia@gmail.com \\ G Geoffrey Booth \\ Eli Broad College of Business Administration, Michigan State University \\ boothg@msu.edu \\ Juha-Pekka Kallunki \\ Oulu Business School, University of Oulu \\ Stockholm School of Economics \\ School of Business, Aalto University \\ juha-pekka.kallunki@oulu.fi
}

April, 26, 2018

Corresponding author:

Kenneth A. Frank, College of Education, Michigan State University, 620 Farm Lane Room 462, East Lansing, MI 48824-1034

Phone: 517-355-9567 Fax: 17-353-6393 e-mail: kenfrank@msu.edu 


\title{
The Market Dynamics of Socially Embedded Trading
}

\begin{abstract}
Social embeddedness has provided a compelling challenge to neoclassical descriptions of markets. Nevertheless, without a corresponding description of the micro-social forces that counter embeddedness, the description of embeddedness is essentially static, and does not integrate the dual forces of embeddedness and markets. In this study we identify a sociological force counter to embeddedness residing in third parties whose presence may interrupt socially embedded informal trading partnerships. Using data from the Helsinki Stock Exchange in 19967, we confirm that stock trades are socially embedded in partnerships in which trading persists from week to week and in which prices deviate from immediate trading prices. Importantly, we find that trading partnerships are more likely to be interrupted when prices deviate from immediate trading prices and when third parties are present who trade with one or both members of the partnership. Thus, third parties are a critical sociological force in the embeddednessmarket dynamic.
\end{abstract}

\section{Keywords}

social embeddedness, third parties, trading partnerships 


\section{The Market Dynamics of Socially Embedded Trading}

\section{Introduction}

Granovetter (1985) challenged the fundamental assumption of neoclassical economic descriptions of markets (e.g., Friedman, 1977) by arguing that economic transactions are embedded in social relationships (see also White, 1981). The social embeddedness literature, however, has yet to rigorously identify the micro-sociological forces that might counter the effects of personal relationships in markets. In the absence of such a description, the embeddedness perspective implicitly relies on perfect information as espoused in neoclassical economics to explain behavior characteristic of markets.

The purpose of this study is to explore empirically a localized and sociologically embedded force that can counter embeddedness. We do so in the context of economic activity among stockbrokers in Finland in the mid 1990's. This environment not only represents the conditions of the neoclassical market in terms of information contained in price, but also it provides a market context where traders knew one another, socialized with one another and worked within a small number of brokerage houses. As a result our study has the potential to provide insights into a dynamic between social embeddedness and neo-classical markets. As pointed out by Glasserman and Young (2016), investigating these types of processes will provide a better understanding of the price contagion that is often observed in financial markets.

Although an idealized market might have the potential to diffuse information in the form of price for transactions conducted at arms' length, Granovetter (1985, p. 505) argues that such arms-length transactions rarely occur, as economic transactions are nearly always socially 


\section{The Market Dynamics of Socially Embedded Trading}

embedded. In examples relevant for this context, financial transactions have been affected by personal relationships among stock traders (Baker, 1984), among heads of major financial institutions French bankers (Frank and Yasumoto, 1998) and among diamond traders (BenPorath, 1980). In the theory and findings of social embeddedness, traders who give preferential treatment based on personal relationships seemingly ignore better prices offered by others. The question then is whether and how competition can enter back into a system in which economic transactions have become socially embedded.

We begin to address how competition enters into socially embedded transactions by investigating the dynamics through which socially embedded trading relationships form and then are interrupted. In particular, we hypothesize that the force that can undermine well-established informal trading partnerships (e.g., two stockbrokers who trade several stocks each week with each other for several weeks) is attributable to the presence of a third party available for transactions with one or both members of the partnership (Burt, 2009; Simmel, 1950;). Correspondingly, members of a trading partnership who trade with a third party experience a force of competition that acts against the partnership. The implication is that third parties are the conduits for the competitive force - where third parties are present socially embedded transactions are less likely to endure and neoclassical market conditions will pertain. And where third parties are absent, socially embedded transactions will endure, thwarting general market forces. Ultimately, our analysis suggests a dynamic in which trading partnerships become socially embedded and then are interrupted in the presence of available third parties.

We test our ideas using unique data that includes all of the upstairs trades made on the Helsinki Stock Exchange (HEX, as it was officially called at the time of our sample period) between January 1996 and December 1997. HEX is split into upstairs and downstairs venues. 


\section{The Market Dynamics of Socially Embedded Trading}

The downstairs market of HEX is an open electronic limit order (an order to buy or sell a stock at a specific price or better) book that is continuously updated by brokers with the limit orders of anonymous customers. Orders specify the price and number of shares the customer wants to transact and are automatically matched to other limit orders according to price and time priority. The details of the transaction are displayed on electronic montages immediately following the match. In this sense the downstairs market has many of the features of the idealized arms-length transactions of the neoclassical market.

Not all transactions, however, can be easily completed in the downstairs market. In particular, a trader who sought to fill unusually large or urgent trades on the downstairs market would immediately alter prices to his client's detriment. For example, if a trader announced on the downstairs market the intent to trade 10,000 shares of Nokia, other traders would likely immediately suspect the seller's (and client's) urgency and would not be compelled to offer the immediate trading price. Furthermore, this behavior could ripple through other trades within the marketplace, causing at least a short term drop in stock price.

Because of the dynamics in the downstairs market, traders with large or especially urgent transactions turn to the more personalized and less conspicuous upstairs market (e.g., Bessembinder and Venkataraman, 2004; Grossman, 1992; Madhaven and Cheng, 1997; Seppi, 1990). The upstairs market, sometimes referred to as a dealer market, consists of brokers employed by brokerage houses who, upon receiving a customer order to trade (usually by phone), look for trade counterparties, finding them either among their own customers or among the customers of other brokers. That is, the trader seeks to distribute large or urgent trades through known counter-traders without signaling urgency and triggering changes in price. Thus, the upstairs market is ideal for our study because its transactions capture a sociological field of 


\section{The Market Dynamics of Socially Embedded Trading}

human interaction (Bourdieu, 1993; Fligstein, 1990, 2001), allowing us to focus on the social dynamics of human trading prior to the emergence of extensive electronic algorithmic trading (i.e., done by computers programmed to execute trades under certain conditions).

The upstairs and downstairs markets are described as folded into one another. First, prices in the upstairs market are bound by bid and ask prices in the downstairs market (e.g., Beunza and Millo, 2013; Bikunle and Armitage, 2015; Booth, et al., 2002; Verousis and Gwilym, 2014). But the folding goes both ways as trades on the upstairs market are electronically posted and can inform trades on the downstairs market. Thus even markets that are highly automated like a downstairs market can reflect the structure of social relationships among traders such as in an upstairs market. Such folding between upstairs and downstairs markets is typical in modern western markets, with the most well-known upstairs markets arguably being associated with the New York Stock Exchange and the London Stock Exchange.

In the next Section we present a basic function for the rationality of the trader in terms of discounts for delayed compensation for a socially embedded trade. We then use the prisoner's dilemma to show how the presence of a third party can alter the rationality of socially embedded trades. From this theory we generate three hypotheses concerning the effects of price and third parties on the interruption of established trading partnerships. We then describe our data and our analytic models in detail. Anticipating our key results, we first establish the tendency for trades to become socially embedded in specific partnerships that deviate from neoclassical economic accounts of markets. We then find that established trading partnerships are more likely to be interrupted when prices deviate from the immediate trading price and when there are third parties present who trade with one or both members of the partnership. 


\section{Rationality of the socially embedded stock broker}

We consider the utility of the stockbroker, using it as the archetypical example of an economic phenomenon that can become socially embedded. The utility of the trader is a function of the commissions the trader obtains from buying or selling stock. Technically, a trader collects this commission regardless of the price at which the stock is traded. Thus it is possible for a trader to increase his/her own utility without increasing the utility of the client who wants to buy at the lowest price possible or sell at the highest price. Nevertheless, traders who consistently perform poorly in terms of price will not be able to attract or retain clients in the long run, and, therefore, will engage in fewer trades and receive fewer commissions and may be forced to leave the market due to lack of business. Therefore we consider favorable prices to be part of the broker's utility.

\section{Rationality in terms of discount factors}

To represent the effect of reputation inherent in a trading partnership, we express a trader's utility as a function of the profits on a given trade relative to expected profits from future trades with the same counterparty. In particular, suppose trader A must decide whether to give a beneficial price to trader B whose client has requested quick sale of a large amount of a specific stock. Trader A could exploit B's position by offering lower than the immediate trading price. But A might choose to offer B the immediate trading price (or even higher), anticipating that B will return the benefit at some future date with a given probability. The goal then is to characterize A's utility in terms of the loss on the current trade versus the potential, but uncertain, gain on a future trade with B. 


\section{The Market Dynamics of Socially Embedded Trading}

To quantify the circumstances under which A would allocate to B consider the discount A assigns to the delayed compensation from B. In particular, the Value (V) to A is a function of the initial value $G$ that $A$ allocates to $B$ and payback $\pi(\pi \geq 0)$ as modified by a discount $1 /(1+\lambda \theta)$ : $\mathrm{V}=\pi \mathrm{G} /(1+\lambda \theta)$

where $\theta$ represents the odds of lack of payback $(\theta \geq 0)$, and $\lambda$ represents risk aversion $(\lambda \geq 0$, ignoring risk seeking). Critically, given the discount, $V \geq G$ if and only if $\pi \geq 1+\lambda \theta$.

The terms in (1) inform how uncertainty can create embeddedness. Given A's uncertainty about future demands, A allows for the possibility that B will compensate A in more than A's original outlay $(\pi>1)$. If this holds, then the value of A's investment of $\mathrm{G}$ depends on whether trader B will payback A in more than the original outlay. The payback may be greater than the initial outlay if trader B values a partnership with A because of a social or emotional attachment to the partnership (Lawler and Yoon, 1996, 1998), or if trader B anticipates some future demand to trade that might be fulfilled by trading with A (Coleman, 1994).

As the prices of trades between A and B deviate from the immediate trading price, an opportunity is created for other traders. In particular, the embeddedness of the trades between A and B in their partnership excludes transactions with other traders willing to trade at the immediate trading price. In response, other traders might seek to transact with $\mathrm{A}$ or $\mathrm{B}$ at the immediate trading price, thereby increasing the volume of shares traded without taking a penalty in price. This suggests our first hypothesis:

$H_{1}$ : A trading partnership is more likely to be interrupted the greater the deviation in prices from the immediate trading price. 


\section{Rationality in terms of the prisoner's dilemma}

Hypothesis 1 describes the forces acting on members of a partnership in terms of price. But the forces may also be conveyed by third parties as understood in the prisoner's dilemma paradigm. Using notation based on Kreps et al. (1982), we illustrate this dilemma in Table 1. In this figure, $\alpha$ is the payoff to a unilateral defector and $\beta$ is the payoff to a unilateral cooperator. For a convenient scale, assume that neither receives a payoff if both defect $(0,0)$, and both receive a payoff of 1 if both cooperate $(1,1)$. Further assume that $\alpha>1$ (there is a benefit to defecting that is greater than bilateral cooperation), $\beta<0$ (there is a cost to cooperating if the other defects), and $\alpha+\beta<2$ (asymmetric strategies are inferior to universal cooperation in terms of overall benefit).

\section{Insert Table 1 here}

Using the terms of the prisoner's dilemma, cooperation occurs when traders make increasing allocations to one another, with each allocation fulfilling the obligation of the previous favor. Defection occurs when trader A refuses a trade with partner B even though the trader A had clients interested in trading stocks traded by B. A direct indicator of defection is when trader A trades outside the partnership for a price that is better than that offered by B. In this sense stock trading is a repeated prisoner's dilemma as each trading cycle each trader decides to cooperate or defect, based on the history and expectation of future of trading.

It is well-proven that the unique Nash equilibrium in the prisoner's dilemma involves each player choosing to defect at every stage (Kreps et al., 1982, p. 246). The proof is based on an endgame argument. On the last trial there is value to defecting because there is nothing to be gained by future cooperation. But if one believes one's partner will defect on the $\mathrm{n}^{\text {th }}$ trial there is 


\section{The Market Dynamics of Socially Embedded Trading}

value in defecting on the $n-1$ trial, preemptively gaining the advantage of defection. Similar logic applies to the n-2 trial, all the way back to the first trial.

While constant defection is rational for both parties in the prisoners' dilemma, Kreps et al. (1982), prove that a cooperation strategy may occur with uncertain information in a repeated prisoner's dilemma (Radner, 1986, makes a similar argument with respect to uncertain strategies and Neyman, 1985, makes a similar argument based on the complexity of the game). An overview of the argument is that there are expected returns to cooperation over repeated future interactions (Axelrod, 1980; Dal Bó and Fréchette, 2018; Murninghan and Roth, 1983). This aligns with the value function in (1). Therefore there is value to cooperating until one encounters an endgame. With uncertainty, it is not clear when the $n^{\text {th }}$ trial will occur, so cooperation is rational until the endgame is clearly present. ${ }^{\mathrm{i}}$

Applying, Kreps' et al. (1982), logic in our context, traders cooperate because of the uncertainty of the demands for future trades and their vulnerability to such demands. Thus they cultivate trading partnerships as a hedge against future demands for extreme trades. The traders are able to maintain their partnerships as long as the uncertainty about the future is high relative to the immediate pay-off for defection. In this sense traders bootstrap their cooperation (Kreps et al., 1982, p.251) facilitating transactions and the functioning of the overall market (Beckert, 2009). See Axelrod (1980) and Cohen Riolo, and Axelrod (2001) for a similar argument about "the shadow of the future" in which the potential for future trading informs current behavior. The question then turns to why the partnership is interrupted in the presence of a third party. The presence of the third party makes the potential for the endgame more immediate and apparent. Thus each member of the partnership anticipates the other is more likely to defect 


\section{The Market Dynamics of Socially Embedded Trading}

when the third party is present, weakening the bootstrap effect. This leads to our second hypothesis:

$\mathrm{H}_{2}$ : A trading partnership is more likely to be interrupted the greater the number of third parties who trade with either member of the partnership.

If this hypothesis holds it would suggest that third parties generate the force to move transactions away from embeddedness and towards neoclassical descriptions of markets. By implication, traders would not react merely to general prices in the market. Instead, they would react to localized forces represented by the third party. Correspondingly, in the absence of a third party, traders may accumulate commitment to socially embedded trades that increasingly deviate from average trading prices in the market.

Why does not A simply trade with C and then return to trading with B? Here we return to rational action within the prisoner's dilemma. We assume that when A trades with third party $\mathrm{C}$ it affects the price and amount of shares A trades with B. In this sense A's trade with C creates a negative externality for B (Binmore and Eguila, 2016; Dijkstra, 2009). This increases the likelihood that the return to B for an earlier allocation to A will be less than the initial allocation. Correspondingly, B will view A as having defected. Given B's view of A's defection, B's commitment to the personal relationship may diminish or disappear. Correspondingly, B will engage in A purely rationally. Moreover, since A defected, B's rational response is to defect as well (Axelrod, 1980). In Axelrod's (1980) terms, B is provocable, which is a rational, effective response. Given the defections of A and B it is likely that they will engage in the purely rational strategy of continued defection.

Note that the force of the third party can be understood in terms of the rationality of discount factors in the previous subsection by applying (1) to all traders. In particular, as $\pi \mathrm{G}$ 


\section{The Market Dynamics of Socially Embedded Trading}

increases through trades between $\mathrm{A}$ and $\mathrm{B}$ other traders can gain in a transaction with $\mathrm{A}$ or $\mathrm{B}$ without relying on future compensation (assuming a full discount for a large $\lambda$ ). To do so, for example, other traders might compete to sell to A. Trader A may then decide that the incentive of other traders overcomes the incentive of potential for future favorable prices available from B and so A trades with other traders.

Note that the third party need not intend to disrupt the partnership. By simply following the function in (1), the third party's trade with A makes A's allocation to B larger relative to A's alternative with the third party. In turn, this increased allocation decreases the probability that A will be compensated by B (Arai, 2009). As a result the more A trades with $\mathrm{C}$ the more likely A is to withdraw from the partnership with B; the mere presence of the third party may interrupt the trading partnership, countering the force that drives trades away from the immediate trading price, and therefore pushing the system to the neoclassical model.

The preceding argument is expressed in the purely rational and immediate context of the prisoner's dilemma and the immediate presence of the third party. A, however, might take revenge against $\mathrm{B}$, which would have evolutionary advantages to reducing further defections (Bendor, 1993; McCullough, Kurzban and Tabak, 2010; Schuman and Ross, 2010). Such actions are especially likely against those with whom one had built up trust and a personal relationship through continued exchange (Granovetter, 1985; Lawlyer and Yoon, 1996, 1998; Molm, 1997). Moreover, the presence of the third party heightens the possibility of revenge (McCullough, Kurzban and Tabak, 2010) because revenge sends a signal to third party C as well as to B. Finally, the continued presence of the third party continually reduces the probability of reciprocity and thus of reconciliation (Aquino, Tripp and Bies, 2006; Cohen, Riolo and Axelrod, 2001; Dijkstra, 2007, generalized core;). 


\section{The Market Dynamics of Socially Embedded Trading}

Critically the force of the third party to compete for trades with members of a partnership may also depend on the third party's relationship with both members of the partnership. First, the third party's offer to trade with A yields more benefit if the third party also is available to trade with B once the A-B partnership is interrupted. Second, the presence of the third party undermines Kreps et al.'s, (1982) bootstrap by making the possibility for defection present and transparent. This holds especially when the third party trades with both members of the partnership, in which case each partner knows that the other is constantly tempted to defect. Thus the mere presence of the third party who trades with both members of a partnership undermines the partnership. This leads to our third hypothesis:

$H_{3}$ : A trading partnership is more likely to be interrupted the greater the number of third parties who trade with both members of the partnership.

To summarize, our theory is that $\mathrm{G}$ and $\pi$ accumulate in the absence of a third party as transactions become increasingly embedded in personal relationships between partners. This allows the members of the partnership to accommodate client demands for large and urgent transactions without engaging the downstairs market. But when a third party is present the deviations from the immediate trading price between the partners become increasingly attractive to third parties who then seek to transact with members of the partnership by offering a better price to one of the partners, while still a preferable price to the third party's client relative to the downstairs market. Given the uncertainty of the future benefits of the partnership, a member of the partnership may choose to trade with the third party. This either directly interrupts the partnership or indirectly through retaliation of the spurned partner. Furthermore, when the third party is commonly available to both members of a partnership the pressure to defect is stronger and more often present. This heightens awareness of the endgame, increasing the chances of defection of either partner. 


\section{The Market Dynamics of Socially Embedded Trading}

\section{The environment}

As noted in the introduction, we test our ideas using unique data that includes all of the upstairs trades made on the Helsinki Stock Exchange (HEX, as it was officially called at the time of our sample period) between January 1996 and December 1997. Our sample is limited to two years because the HEX stopped publicly providing the code identifying the individual traders involved in each trade after 1997. Two years, however, is long enough for us to observe the repeated transactions among traders through which they establish and then interrupt partnerships. We define an informal partnership as a relationship that involves repeated economic transactions. This differentiates it from a formal partnership with contractual obligations and from a relationship (e.g., friendships that may not involve economic transactions).

By way of background, HEX, as well as all of the other Finnish financial markets, was subject to the strong control of public authorities until the early 1980's and was underdeveloped compared to major western countries. Joining many countries in the 1980's and 90's, Finland began to liberalize its financial markets allowing participation from other countries, which lessened the influence of financial intermediaries and increased the reliance of Finnish companies on equity financing (Kallunki and Martikainen, 1997). The liberalization took years to accomplish but was essentially complete by the middle 1990's (Oxelheim, 2000). For instance, the Security Market Act was established in 1989 and was amended in 1996 to comply with various European Directives pertaining to market risks and investment services. In 1990, the stock exchange created HETI, its Automated Trading and Information Systems. Also, rules restricting ownership of Finnish stocks by foreign investors were abolished in 1993, which increased foreign ownership from slightly less than 20\% in 1993 to around 60\% in 1996 


\section{The Market Dynamics of Socially Embedded Trading}

(Oikarinen, 2010). ${ }^{\text {ii }}$ Taken together these market changes resulted in HEX increasing not only the number of stocks listed and corresponding trading volumes but also the number of active buyers and sellers. Thus by 1996 the HEX became an open market with potential for neoclassical conditions.

\section{Stock exchange data}

\section{HEX trades using HETI}

For each stock transaction, the HETI records the price, volume, time, and venue (upstairs or downstairs), as well as the traders and brokerage houses on both sides of the transaction, with HETI's design ensuring that we have no missing data. During our sample period, there were 104 stocks listed in HEX representing approximately 83 companies. The exchange was served by 25 brokerage houses, with eight owned by full-scale banks and the remaining 17 being independently owned. The majority of the houses were Finnish owned but some were owned by other European financial institutions. Examples of the brokerage houses using the HEX facilities include Merita Pankkiiriliike, Evli Pankki, and Williams De Broe Pankkiiriliike. The 25 houses employed 116 brokers to execute stock transactions. The brokers were not identified by name in our data; instead each broker was assigned an identification code attached to each transaction.

We restrict our analyses to the top 34 most traded stocks to ensure that we have sufficiently active trades for analysis. These are the stocks of well-known international companies such as Nokia (telecommunications), Enso (forest products and now known as StoraEnso), and Outokumpu (metals and minerals). Our top 34 stocks contain 19 of the top 20 stocks in the Finnish market index, the HEX-20 (the exception is Kyro, which was traded only 12 times in our two years of data), and account for about $83 \%$ of all trades and $92 \%$ of all partnerships in our data. As such, these stocks are actively traded at levels relevant for testing our theory. 


\section{The Market Dynamics of Socially Embedded Trading}

Stocks traded less frequently are specialty stocks for which there are constrained opportunities for trades in a given week on the upstairs market. Thus the traders who are asked by their clients to sell such stocks may not have choices among counterparties. In particular, only the top 34 stocks are involved in more than 2.5 trades per week because this typically creates the condition for two trades in a given week which are necessary for three parties to be involved. All others were traded less than 2.5 times per week, suggesting a constraint on trading partners and availability of third parties interested in trading the same stocks. Furthermore, highly constrained trades convey little information in a market sense because other traders are not engaged in the same stock. The price only has meaning for, and is determined by, the two traders involved. Therefore trades in the top 34 stocks best represent the social and market dynamics we seek to study. ${ }^{\text {iii }}$ Nevertheless, the inferences from our main model regarding our first three hypotheses are sustained when we use all trades rather than the most frequently traded stocks (results are reported in technical appendix B).

To gain an intuition for the nature of our data, consider Table 2 which contains the information we have for all the upstairs trades of Nokia (NOKAV) on June 18, 1997, the date of the largest trading volume in 1997. The table includes the buyer and seller and the brokerage house of each, the date, time, the stock, number of shares, and price. For example, buyer 20 in house 3 bought 2,000 shares from seller 33 in house 17 for 36,100 pennis per share at 12:46 pm (the prices reported in Table 2 are reported in pennis with 36,100 pennis equal to 361 markka, which was around $\$ 72$ at the time of our data). As we describe in the next section, the fine granular level of data allows us to identify the emergence and interruption of trading partnerships, the advantage of a trade in terms of price and shares, the presence of third party traders, as well as institutional effects of brokerage houses. 


\section{The Market Dynamics of Socially Embedded Trading \\ Insert Table 2 Here}

\section{Measures}

\section{Dependent variable}

Interruption of a trading partnership. Our dependent variable is an indicator of whether traders who established a trading partnership suspended their trades with one another, thus interrupting the partnership. We define a trading partnership as a pair of traders who trade with each other at least once a week for at least two consecutive weeks. This includes shares sold from $\mathrm{A}$ to $\mathrm{B}$ and from $\mathrm{B}$ to $\mathrm{A}$ and therefore there is only one observation per pair of traders.

In Figure 1 we show the flow of data to define our analytic sample. There were more than 46,000 possible pairs over seven fiscal quarters (we omit the first quarter because our models

include lagged variables that we could not measure relative to the first quarter). Of those, 1,293 established a trading partnership over at least two weeks. Of those about $9 \%$ (120) suspended their trading for at least two weeks. Defining interruption as suspended trading of at least one week could reflect incidental events (e.g., being ill, on vacation, or attending to personal matters) not related to deliberate choices. On the other hand, given that the average trader trades roughly 68 times per week, a suspension of two weeks is a long enough interval to indicate intent regarding the partnership. In Appendix A, we show the distribution of interrupted partnerships if we define them as suspended trades for one week (43\%) or three weeks $(4 \%)$ and in our robustness checks we examine models in which interruption is defined by a one week or three week interval (Appendix C).

\section{Insert Figure 1 Here.}




\section{Key predictor (independent) variables}

Deviation in price $x$ shares traded. The neoclassical economic model suggests that the greater the deviations from average trading price the more benefit for other traders to compete

for transactions with members of the partnership, and thus the more vulnerable the partnership to interruption, as in our first hypothesis. Therefore we test our first hypothesis using the deviation of price from the $\underline{\text { Volume }} \underline{\text { Weighted }} \underline{\text { Average }}$ Price for the week (i.e., VWAP, which is a common practitioner measure for a trader's transaction performance involving multiple trades). In particular we use $\mid$ price-VWAP $\mid \mathrm{x}$ (thousands of shares traded) to predict the interruption of a partnership. Thus, the measure accounts for the value of the overall trade relative to the market. Furthermore, because it is a function of shares traded as well as price it reflects the utility of the trader and client.

Number of Asymmetric third parties who traded with only one member of the partnership. Our second hypothesis is that partnerships are more vulnerable the more others are available to compete on price. Therefore we control for the total number third parties, C, members of a partnership A and B traded within the previous quarter. Third parties C who traded with A or B but not both may compete on price, but without the leverage or advantage of those who traded with both A and B. Therefore, to be counted as an asymmetric third party, C could trade with A or B but not both.

Number of Common Third Parties. Our third hypothesis concerns the effect of common third parties $\mathrm{C}$ on an interrupted partnership. We consider the third party $\mathrm{C}$ as available to both members of the partnership A and B if C traded with A and B at least once in a given quarter (we retain the restriction to the 34 most frequently traded stocks to avoid constrained trades in stocks with limited volume). 


\section{The Market Dynamics of Socially Embedded Trading}

Following the relational event framework (Butts, 2008; de Nooy, 2011), third party presence is defined in the quarter preceding the measurement of whether or not a trading partnership was interrupted. For example, a trader was present as a third party to an A-B partnership in the second quarter if the trader traded with A or B in at least one week in the first quarter. Consistent with the use of triadic counts in exponential random graph models (Robins et al., 2007), the variables are a count of the number of third parties who traded with members of a partnership. ${ }^{\text {iv }}$ We also tested for interactions between deviation in price per thousands of shares traded and each of the measures of third parties but none were statistically significant in any of our models.

\section{Covariates}

Membership in the Same Brokerage House. Generally, market transactions can be shaped by organizations (e.g., Padgett and Powell, 2012). In particular, brokerage houses secure both the buy and sell commissions from a transaction when the trade is made in-house. This potentially creates a strong incentive for traders to trade with themselves or with members of the same firm. As a result, intra-firm partnerships may be more likely to persist. On the other hand, traders who form a partnership between brokerage houses may have an especially strong personal bond, making the partnership more likely to persist. To control for either effect, we include membership in the same brokerage house, defining the variable as coded 1 if the pair of traders were employed in the same house and 0 otherwise. By representing relationships contained within the formal organization this covariate can also capture many deeper network structures beyond the triad. Note also that this covariate is nearly constant within a given quarter and is defined in the same quarter as the outcome because the associated incentives would apply during the time of trades within the partnership. 


\section{The Market Dynamics of Socially Embedded Trading}

Membership in the same Network Clique. The effects of social structure may be conveyed by network pathways longer than the 2-path lengths defined by common third parties (e.g., A-BC). In particular, traders may organize themselves into informal subgroups or cliques that convey norms against hostile actions (Frank and Yasumoto, 1998; Kadushin, 1995).

Correspondingly we identified subgroups in the partnership network using Frank's $(1995,1996)$ community detection algorithm. The algorithm iteratively assigns actors to cliques to maximize the concentration of partnerships within cliques with sparse partnerships between cliques. In particular, it iteratively reassigns actors to cliques to maximize the odds that any given partnership occurs within a clique versus between cliques. In this sense it maximizes a parameter from models such as Exponential Random Graph Models (Robins et al., 2007) used for network analysis (Frank, 1995). We applied the algorithm separately to the partnership data for each quarter, i.e., the input listed the pairs of traders who had formed at least one partnership in a given quarter. The output was then the clique to which each trader belonged based on the partnership data in that quarter. The predictor in our model was then an indicator of whether members of a partnership were members of the same clique or not in the previous quarter.

Because informal clique memberships and formal brokerage house memberships overlapped considerably, we constructed three indicators in our final models: 1) membership in the same informal clique but not in the same brokerage house; 2) membership in the same brokerage house but not same informal clique; and 3) membership in both the same informal clique and same brokerage house.

\# of Weeks of Continuous Trading through Previous Week. In our theory discussion we posit an increasing value of allocations as traders become more deeply embedded in a partnership over time. Thus, one of our key predictors is the size of the allocations in the form of 


\section{The Market Dynamics of Socially Embedded Trading}

the deviation in price from the average price for that week. Because traders may become attached to the relationship itself through repeated trades (Lawler and Yoon 1996, 1998), we control for the number of continuous weeks of prior trading at least once a week observed in a partnership.

\section{Plan of analysis}

In the preliminary analyses we evaluate the prima facie case for social embeddedness. First we examine the tendency for traders to trade in consecutive weeks. We then examine the relationship between number of consecutive weeks traded and stock price as it deviated from the VWAP. These analyses were conducted for each dyad of traders $(6,441)$ for each week after the first week (104) for a total sample of roughly 660,000.

Our first three hypotheses concern the effects of deviations in price from VWAP and the presence of third parties on established trading partnerships. Given that our outcome is defined only after four weeks: two weeks of consecutive trading and then two of interrupted trading, the phenomenon cannot easily be bound within a single week or month. Therefore we used quarters to define the social context in which traders likely operated to smooth over previously mentioned short term deviations relating to personal issues or thin trading. Furthermore, the quarter is a natural unit for traders as there are typically quarterly (as well as monthly) reports by firms to keep track of individual trader performance on an on-going aggregate basis.

Following the discrete relational event framework (de Nooy, 2011), we organize the data into eight fiscal quarters representing subperiods and model trading behavior between members of a partnership as a function of social context in the previous quarter. For example, we modeled whether a partnership between A and B was interrupted in the fourth quarter as a function of how 


\section{The Market Dynamics of Socially Embedded Trading}

many third parties A and B both traded with in the third quarter (we do not analyze outcomes from the first quarter for which we have no data on prior third party trading).

We begin by presenting descriptive statistics, and then we estimate relational event models (de Nooy, 2011) for whether traders $a$ and $b$ interrupted their partnership by suspending trading in week $t$ within quarter $q$ (relational event models are network extensions of event history models) Note that pairs of traders can appear in our data more than once. Consider pair A and B who traded for two weeks, then interrupted trading for two weeks. This is one episode. But A and B may then resume trading for several weeks and then interrupt trading a second time. This constitutes a second episode and so on.

We control for the pair with a random effect because given the 516 pairs with repeated episodes fixed effects would tax the degrees of freedom. But we do estimate a subsequent model equivalent to fixed effects using adaptive centering (Raudenbush, 2009) we describe below. We use a linear probability model for ease of estimation and interpretation. Specifically, for week $t$ and pair $a b$ in quarter $q$ we have:

$\mathrm{P}(\text { interrupted trading partnership })_{\text {tabq }}=\beta_{0}+$

$+\beta_{1}$ Deviation in price $x$ thousands of shares traded tabq

$+\beta_{2}$ Number of common third parties ${ }_{a b q-1}$

$+\beta_{3}$ Number of asymmetric third parties $a b q-1$

$+\beta_{4}$ Same brokerage house onlyabq

$+\beta_{5}$ Same trading clique only $a b q-1$

$+\beta_{6}$ Same brokerage house and same trading clique tabq-1

$+\beta_{7}$ Number of weeks of continuous trading tabq

$$
+\alpha_{q}+\tau_{a}+v_{b}+\mu_{a b q}+\mathrm{e}_{t a b q} .
$$




\section{The Market Dynamics of Socially Embedded Trading}

Following the relational event framework (de Nooy, 20911), in (2), $\alpha_{q}$ are fixed effects for fiscal quarters, and $\tau_{a}$ and $v_{b}$ are random effects (assumed to be normally distributed with mean 0 and estimated variance) for each trader (that would account for differences among traders' tendencies to interrupt partnerships such as due to the volume of trades or psychological profiles of the traders). The $u_{0 a b q}$ are the random effects for the pairs of traders who established trading partnerships on more than one occasion within a given quarter (DuBois et al., 2013) and the $\mathrm{e}_{t a b q}$ are error terms for week $t$ for pair $a b$ in quarter $q$. We used the HLM software (Raudenbush and Bryk, 2002) to estimate the model with random effects. ${ }^{\mathrm{v}}$

We recognize that while our data has great strengths, it does not contain extensive information about potential alternative explanations for the interruption of a partnership. For example, it could be that two traders who were stable and enduring friends were more likely to persist in their partnership as well as avoid trading with third parties who could interrupt the partnership. Therefore it could be that friendship is the causal factor, not the common third party. $^{\text {vi }}$

In response to concerns about alternative explanations for our inferences, we take two steps. First, we estimate a second model using adaptive centering (Raudenbush, 2009), in which all of the predictors are centered around their pair level means for a particular quarter. This is comparable to a model with fixed effects for pairs by quarters, leveraging the pairs that formed more than one partnership to evaluate the effects of the presence of common third parties controlling for any aspect of the pair that was constant across the quarter (because only 516 out of 1,293 pairs had more than one partnership episode we did not use this as our main model). This model essentially allows us to estimate the effect of time varying covariates on the interruption of specific partnership episodes in contrast to the first model that estimates effects 


\section{The Market Dynamics of Socially Embedded Trading}

associated with a general instability of partnerships for a pair of traders. Second, recognizing the potential for bias in our estimates even after employing our controls, we quantify how much bias there must have been in our estimates to invalidate our inferences (Frank et al., 2013). Details of this approach are given in the results section.

\section{Results}

\section{Preliminary analyses}

Table 3 shows the odds that two traders traded in a given week were 250 times greater if the traders traded in the previous week than if they did not $(\mathrm{p} \leq .001)$. Table 4 shows the absolute value of the difference between the price of a given trade and the VWAP increased about 6 pennis for each week of continuous trading $(\mathrm{p} \leq .001)$. Given the standard deviation for weeks of continuous trading (5.037) and the standard deviation of deviation of price from average (323.734), a one standard deviation increase in weeks of continuous trading translated to about a tenth of an increase in a standard deviation in price deviation. ${ }^{\text {vi }}$ These results support the social embeddedness challenge to the neoclassical description of markets; traders are more likely to trade with previous partners, and the longer the trading relationship the more the traders trade in prices that deviate from the general market (Baker, 1984; Kirman, 2001). That is, Table 4 shows the accumulation of values of $\mathrm{G}$ and $\pi$ the more traders trade with one another as prices increasingly deviate from VWAP with each week of uninterrupted trading between a pair of traders.

\section{Insert Tables 3 and 4 Here.}

\section{Effects on trading partnerships}




\section{The Market Dynamics of Socially Embedded Trading}

Table 5 shows the descriptive statistics for our sample of 1,293 partnerships across seven fiscal quarters of our data. Consistent with Figure 1, approximately $9 \%$ of the partnerships were interrupted for at least two weeks. The Deviation in Price x Thousands of Shares Traded had a mean of 353 and standard deviation of 202 representing the range in overall value of trades. On average a given partnership had 11 asymmetric third parties who traded with only one member of a partnership, while both members of a partnership traded with on average four common others. Note that the standard deviation for the presence of common third parties was 2.5 -- about $20 \%$ of the partnerships traded with zero common third parties while some traded with up to 20 common third parties. About eight percent of the pairs were members of the same brokerage house but not the same trading clique during a quarter; seven percent were members of the same trading clique but not the same brokerage house; and 30\% were members of both the same brokerage house and same trading clique. The increasing means of the quarters over time indicate increased partnerships due to the heightened activity of the Helsinki exchange during the period of our study. We control for activity associated with quarters using fixed effects in our analysis.

\section{Insert Table 5 Here.}

The results concerning hypotheses 1-3 are shown in Table 6. Regarding our first hypothesis, the estimated effect of Deviation in Price x Thousands of Shares Traded is -.076 in Model $1(\mathrm{p} \leq .01)$. For each pennis deviation per one thousand shares the probability of interruption goes down 7.6\%. This is not consistent with our first hypothesis. The negative estimate for Deviation in Price x Thousands of Shares Traded in Model 1 may be in part because partnerships that deviate in price $\mathrm{x}$ thousands of shares are inherently stable. That is, the more stable the partnership the more willing they are to depart in price $\mathrm{x}$ thousands of shares. 


\section{The Market Dynamics of Socially Embedded Trading}

\section{Insert Table 6 Here.}

The second model uses adaptive centering to define each predictor relative to the mean for the pair of actors. As such, each predictor inherently conditions on the general stability of the partnership. In Model 2 we observe that any given occurrence of partnership within a given pair is more likely (coefficient of .133) to be interrupted the greater the deviation in price $\mathrm{x}$ shares relative to the norm for that pair (the coefficients for Deviation in Price $\mathrm{x}$ Thousands of Shares Traded in models 1 and 2 are statistically different from one another using a Cohen and Cohen, 1983, or Wald test with $\mathrm{p} \leq .001$ ). This suggests the larger the deviation in Price $\mathrm{x}$ Thousands of Shares for a given pair the more stable was that pair (the negative coefficient from Model 1) but that any given deviation from the norm for that pair made the partnership in that episode relatively unstable (the positive coefficient in Model 2). Thus the evidence is mixed regarding our second hypothesis, although the stronger causal evidence is in Model 2 which supports the hypothesis.

Regarding our second hypothesis, Model 1 shows that for the presence of each asymmetric third party the probability of an interrupted partnership increases by about $1 \%(\mathrm{p} \leq$ .001). For a one standard deviation increase in asymmetric third parties, the probability of interruption increased by about $3 \%$ (standard deviation $=2.77$ from Table $5, .012 \times 2.77=.033$ ). Therefore, the base rate of $9 \%$ interruption would be expected to increase by about a third for a one standard deviation increase in asymmetric third parties. This supports our second hypothesis. Interestingly, the estimated effect of asymmetric third parties is reduced to essentially zero for Model 2 with adaptive centering (the coefficients for asymmetric third parties are significantly different between Models 1 and 2, $\mathrm{p} \leq .002$ using a Cohen and Cohen 1983, or Wald test). This 


\section{The Market Dynamics of Socially Embedded Trading}

suggests that the effect of the asymmetric third party may be due in part to the fact that partnerships that engage in trades with asymmetric third parties are inherently unstable (as in Model 1) regardless of the immediate presence of the asymmetric third party (as in Model 2). Regarding our third hypothesis, for each common third party who traded with both members of a partnership, the probability that the partnership would be interrupted increased about $2 \%$. For a one standard deviation increase in common third parties, the probability of interruption increased by about $4.5 \%$ (standard deviation $=2.52$ from Table $5, .018 \times 2.52=.045)$. Therefore, the base rate of $9 \%$ interruption would be expected to increase by about half for a one standard deviation increase in common third parties. This supports our third hypothesis.

In Model (2) with adaptive centering the estimated effect of common third parties is reduced by about $17 \%$ but the inference is retained $(\mathrm{p} \leq .001)$. That is, conditioning on the pair's tendency to interrupt their partnerships, any given partnership episode for a given pair is more likely to be interrupted the more common third parties are present. Thus the common third party effect appears to apply to the general instability of a partnership as well as to the instability specific to a particular episode. In sum, the evidence is especially strong supporting hypothesis 3 concerning the effect of common third parties on interrupted partnerships.

\section{Quantifying the robustness of our inferences}

Even after controlling for characteristics common to the pair through adaptive centering there could still be alternative explanations to our findings due to potentially omitted variables. In response, we use the framework of Frank et al. (2013) to quantify the robustness of our inferences. This framework evaluates the estimated effect against the threshold for making an inference. We begin by applying the sensitivity analysis to our strongest inference, that for 


\section{The Market Dynamics of Socially Embedded Trading}

number of common third parties. From the first column of Table 6 , using a t-critical value of 1.96 and standard error of .0027 (rounded to .003 in Table 6) the threshold for statistical significance is $1.96 * .0027=.0053$. Correspondingly, the estimated effect of common third parties,.018158, exceeds the threshold by $71 \%(.018158-.005309) / .018158=.71$. Following Frank et al. (2013) and using Frank (2014), to invalidate our inference of an effect of common third parties on the interruption of a partnership 71\% of the observed cases (about 538 partnerships) would have to be replaced with partnerships in which there was no relationship between common third parties and the interruption of the partnership. The percent bias to invalidate the inference of $71 \%$ is greater than the number of partnerships occurring in the second through sixth quarters of data, a considerable portion of the phenomenon we seek to study. Furthermore, the level of robustness is greater than three fourths of the observational studies reported in Frank et al. (2013). Using similar calculations, to invalidate the inference of an effect of common third parties in interrupted partnerships in the model with adaptive centering, $39 \%$ of the cases would have to be replaced with zero effect cases.

Regarding hypothesis 1 , to invalidate the inference that Deviation in Price $\mathrm{x}$ Thousands of Shares Traded affects the interruption of a partnership from model (1), $28 \%$ of the estimated effect would have to be due to bias, and $20 \%$ in the model with adaptive centering. Regarding hypothesis two, to invalidate the inference that the presence of asymmetric third parties interrupts partnerships from model (1), $56 \%$ of the estimated effect would have to be due to bias. The estimated effect of asymmetric third parties is not statistically significant in Model 2 with centering. To sustain an inference rejecting a null hypothesis, half the estimate would have to be due to bias. 


\section{The Market Dynamics of Socially Embedded Trading}

\section{Sensitivity checks}

Pertaining to the use of all stocks versus only the top 34, all inferences are identical using $\mathrm{p} \leq .05$ (see technical appendix B). Pertaining to defining interruption based on suspended trading of different time intervals, most are consistent with some exceptions (see technical appendix C). In particular, the estimated effects for Deviation in Price $\mathrm{x}$ Thousands of Shares Traded are negative (but not statistically significant) in the uncentered models in which interruption is defined as one week or three weeks instead of two. Furthermore, in the centered model the estimate for the one week gap is positive but not statistically significant the estimate. Thus the evidence for hypothesis one is strongest using a two week interval to define an interrupted partnership. The inferences regarding the effects of asymmetric third parties are identical across the different specifications using $(\mathrm{p} \leq .05)$. The inferences regarding common third parties are identical except that $\mathrm{p}=.073$ for the one week model with adaptive centering.

Ultimately, our results suggest it is not purely market forces as represented by deviation in price that interrupts a partnership. Part of the force interrupting partnerships is conveyed by the presence of third parties who are available to compete for trades with members of a partnership. By implication, partnerships that do not have steady third parties available (either common third parties or asymmetric third parties) may continue trading at increasingly large deviations from market averages as their trades become socially embedded.

\section{Discussion and concluding remarks}

Our findings suggest that trades become socially embedded as traders prefer continuity in partners and give preferential prices to partners. Partnerships, however, can be interrupted when prices deviate from the immediate trading price and by the presence of third parties who trade 


\section{The Market Dynamics of Socially Embedded Trading}

with both members of the partnership. Merely in their presence third parties represent the competitive force of the neoclassical market behavior, counterbalancing forces of social embeddedness.

Our findings have important implications for the dynamics of embeddedness. While Granovetter (1985: 490) compellingly described the embeddedness of economic actions in social relations, his description is static, "stressing the role of concrete personal relations and structures". In contrast, as we identify the dynamic forces that can encourage or impede social embeddedness, we recognize that social embeddedness is itself dynamic. This is what allows us to recognize that economic transactions can turn toward neoclassical market conditions or embeddedness depending on the presence and action of third parties as well as price deviations. In this sense actors can alternate in the wavering middle ground between pure embeddedness and pure market transactions (Ebenhöh and Pahl-Wostl, 2008; Ostrom, 2004) .

Our findings have important implications for forces conveyed by the general market versus immediate networks. In the neoclassical economic model action is signaled by price to create trading conditions, and is examined through equilibrium mathematics. We find some evidence for an effect of price on interrupting a trading partnership. But we also find that market forces are attributable to a human presence as empirically observed when trading partners react to the presence of third parties. Mathematical models based on neoclassical economics may still closely predict some equilibria. But here we complement such models by using our micro-level data to identify the sociological forces through which price can operate to interrupt socially embedded transactions. That is, market participants may experience market pressures through those in their immediate networks as much as they experience them through aggregate market conditions represented in price. 


\section{The Market Dynamics of Socially Embedded Trading}

The embeddedness market-dynamic also has potentially profound implications for equilibria. Where partnerships are protected from common third parties social embeddedness may endure, persistently thwarting neoclassical economic forces. This can result in isolated markets or simple dyads distinct from the full system of transactions (Kirman, 2001). Thus, together, the forces of partnerships and third parties contribute to a dynamic that creates a complex system rather than a simple asymptotic equilibrium generated by arms-length transactions (Ahrne et al., 2014; White, 2002).

The capacity of third parties to interrupt embedded partnerships has important implications for overall markets. If partnerships are more likely to persist when third parties are present there would be a tendency for clustering at the system level because triadic relationships are the foundation for clusters (e.g., Davis, 1970; Holland and Leinhardt, 1981). Such a presence of clustering would inhibit the flow of information (Callaway et al., 2000; Macy et al., 2003). Because we find that trading triads are unlikely to persist clustering is unlikely to be sustained. On one hand this contributes to the neoclassical market conditions as third parties contain information in the form of price to embedded partnerships. On the other, triads and clustering can protect the system against undesirable diffusion or vulnerability to the actions of a small number of actors (e.g., May, 1973) such as occurred in the subprime credit crisis (Longstaff, 2010). That is, the presence of third parties in breaking up dyadic partnerships may make markets less resilient to failures of individual banks and other financial institutions. Thus our orientation towards more macro processes is through the interplay between dyadic partnership and market forces, not through the social cohesion built up through triads that may have evolutionary advantages (e.g., Yoon, Thye, and Lawler, 2013). 


\section{The Market Dynamics of Socially Embedded Trading}

As we earlier indicated, our data predate the presence of rapid computerized trading. Some might consider this a limitation because a contemporary study would account for the dynamics of computerized trades on upstairs and downstairs markets and on the social structures of traders. Moreover, upstairs markets are often essential for large and urgent trades. Finally, from a broader perspective, our data offer a rare glimpse into the forces that shape the formation of partnerships and effects of price deviations as well as third parties on market phenomena. The forces that shape the underlying dynamics of financial transactions in the Helsinki Stock Exchange of the 1990's may represent similar forces that influence and perhaps even control other non-monetary, but socially salience transactions such as those pertaining to real estate (Halpern, 1996), corporate headhunting (Finlay and Coverdill, 2000), farming (Southall, 1978), or in emerging markets (London and Hart, 2004). In particular, as markets have become prevalent institutions concerning resource flows and coordination (Ahrne et al., 2014) the effect of the presence of third parties on members of a partnership may be as fundamental as the tendency towards social embeddedness precisely because the opportunity for the third party is borne of the favors conferred to a preferred partner. These counteracting forces explain the social and economic dynamics of embeddedness.

We have identified both the tendency for trades to be socially embedded in partnerships and the price and third party forces that push traders away from socially embedded transactions towards neoclassical market conditions. Our results confirm our theory that third parties can counteract the force of embeddedness. Thus the third parties ultimately distribute information into the market. But the information is not perfectly distributed - it goes primarily where the third party conveys it. Our study, therefore, suggests that micro sociological forces can affect the final distribution of information as represented by prices in markets. 
Acknowledgements

We thank Ezra Zuckerman and Ray Reagans for comments given at an MIT Sloan Business School colloquium on a very preliminary version of this work. An earlier version of this paper was also given at the Michigan State Measurement and Quantitative Methods Research colloquium where many thoughtful suggestions were made. 


\section{The Market Dynamics of Socially Embedded Trading}

\section{References}

Ahrne G, Aspers P and Brunsson N (2014) The organization of markets. Organization Studies 36(1): 7-27.

Aquino K, Tripp TM and Bies RJ (2006) Getting even or moving on? Power, procedural justice, and types of offense as predictors of revenge, forgiveness, reconciliation, and avoidance in organizations. Journal of Applied Psychology 91(3): 653-668.

Arai K (2009) Defining trust using expected utility theory. Hitotsubashi Journal of Economics 50(2): 99-118.

Axelrod, R (1980) More effective choice in the prisoner's dilemma. Journal of Conflict Resolution 24(3): 379-403.

Baker WE (1984) The social structure of a national securities market. American Journal of Sociology 89(4): 775-811.

Beckert J (2009) The social order of markets. Theory and Society 38(3): 245-269.

Ben-Porath Y (1980) The F-connection: Families, friends, and firms and the organization of exchange. Population and Development Review 6(1): 1-30.

Bendor, J (1993) Uncertainty and the evolution of cooperation. Journal of Conflict Resolution 37(4): 709-734.

Bessimbinder H and Venkataraman K (2004) Does an electronic stock exchange need an upstairs market? Journal of Financial Economics 73(1): 3-36.

Beunza D and Yuval M (2013) Folding: Integrating algorithms into the floor of the New York Stock Exchange. Available at SSRN: http://faculty.chicagobooth.edu/workshops/orgsmarkets/past/pdf/Beunza_\%20Folding.docx.

Bikunle G and Armitage S (2015) Price discovery in London's upstairs equity market. Working paper, University of Edinburgh Business School, Edinburgh, UK.

Binmore K and Eguia JX (2016) Bargaining with Outside Options. In: Schofield N and Caballero G (eds) State, Institutions and Democracy. Basel, Switzerland: Springer International Publishing, pp. 3-16.

Booth GG, Lin JC, Martikainen T and Tse Y (2002) Trading and pricing in an upstairs market. Review of Financial Studies 15(4): 1111-1135.

Bourdieu P (1993) The Field of Cultural Production: Essays on Art and Literature. New York, NY: Columbia University Press.

Burt RS (2009) Structural Holes: The Social Structure of Competition. Cambridge, MA: Harvard University Press.

Butts CT (2008) A relational event framework for social action. Sociological Methodology 38(1): 155-200.

Callaway DS, Newman MEJ, Strogatz SH and Watts DJ (2000) Network robustness and fragility: Percolation on random graphs. Physical Review Letters 85(25): 5468-5472.

Cohen MD, Riolo RL and Axelrod R (2001) The role of social structure in the maintenance of cooperative regimes. Rationality and Society, 3(1): 5-32.

Cohen, J., \& Cohen, P. (1983). Applied multiple regression/correlation analysis for the behavioral sciences. Hillsdale, NJ: Erlbaum. 


\section{The Market Dynamics of Socially Embedded Trading}

Coleman JS (1994) Foundations of Social Theory. Cambridge, MA.: Harvard University Press.

Dal Bó P and Fréchette G (2018). On the determinants of cooperation in infinitely repeated games: A survey. Journal of Economic Literature 56(1), 60-114.

Davis JA (1970) Clustering and hierarchy in interpersonal relations: Testing two graph theoretical models on 742 sociomatrices. American Sociological Review 35(5): 843-851.

De Nooy W (2011) Networks of action and events over time: A multilevel discrete-time event history model for longitudinal network data. Social Networks 33(1): 31-40.

De Quillacq LM (1992) The Power Brokers: An Insider's Guide to the French Financial Elite. Dublin, Ireland: Lafferty Publications Ltd.

Dijkstra J (2007) The effects of externalities on partner choice and payoffs in exchange networks. ICS dissertation, Groningen, The Netherlands: University Groningen.

Dijkstra J (2009) Externalities in exchange networks an adaptation of existing theories of exchange networks. Rationality and Society 21(4): 395-427.

DuBois C, Butts CT, McFarland D and Smyth P (2013) Hierarchical models for relational event sequences. Journal of Mathematical Psychology 57(6): 297-309.

Ebenhöh E and Pahl-Wostl C (2008) Agent behavior between maximization and cooperation. Rationality and Society 20(2): 227-252.

Finlay W and Coverdill JE (2000) Risk, opportunism and structural holes: How headhunters manage clients and earn fees. Work and Occupations 27(3): 377-405.

Fligstein N (1990) The Transformation of Corporate Control. Cambridge, MA: Harvard University Press.

Fligstein N (2001) Social skill and the theory of fields. Sociological Theory 19(2): 105-125.

Foley P, Mather C and Neis B (2015) Governing enclosure for coastal communities: Social embeddedness in a Canadian shrimp fishery. Marine Policy 61: 390-400.

Frank KA (2014) KonFound-it!. Available at: www.msu.edu/ kenfrank/research.htm\#causal

Frank. KA (1995) Identifying cohesive subgroups. Social Networks 17: 27-56.

Frank, K. (1996) Mapping interactions within and between cohesive subgroups. Social Networks 18: 93-119.

Frank, KA, Maroulis, S, Duong, M, and Kelcey, B. (2013). What would it take to Change an Inference?: Using Rubin's Causal Model to Interpret the Robustness of Causal Inferences. Education, Evaluation and Policy Analysis. Vol 35: 437-460.

Frank KA and Yasumoto J (1998) Linking action to social structure within a system: Social capital within and between subgroups. American Journal of Sociology 104(3): 642-686.

Friedman M (1977) Adam Smith's relevance for today. Challenge 20(1): 6-12.

Glasserman P and Young HP (2016) Contagion in financial networks. Journal of Economic Literature 54(3): 779-831.

Granovetter M (1985) Economic action and social structure: The problem of embeddedness. American Journal of Sociology 91(3): 481-510.

Grossman SJ (1992) The informational role of upstairs and downstairs trading. The Journal of Business 65(4): 509-528. 


\section{The Market Dynamics of Socially Embedded Trading}

Halpern JJ (1996) The effect of friendship on decisions: Field studies of real estate transactions. Human Relations 49(12): 1519-1547.

Holland PW and Leinhardt S (1981) An exponential family of probability distributions for directed graphs. Journal of the American Statistical Association 76(373): 33-50.

Kadushin C (1995) Friendship among the French financial elite. American Sociological Review, 60: 202-221.

Kallunki JP and Martikainen T (1997) Financial market liberalization and the relationship between stock returns and financial leverage in Finland. Applied Economics Letters 4(1): $19-21$.

Kirman A (2001) Market organization and individual behavior: Evidence from fish markets. In: Rauch JE and Casella A (eds) Networks and Markets. New York, NY: Russell Sage Foundation, pp. 155-195.

Kreps DM, Milgrom P, Roberts J and Wilson, R (1982) Rational cooperation in the finitely repeated prisoners' dilemma. Journal of Economic Theory 27(2): 245-252.

Lawler EJ and Yoon J (1996) Commitment in exchange relations: Test of a theory of relational cohesion. American Sociological Review 61(1): 89-108.

Lawler EJ and Yoon J (1998) Network structure and emotion in exchange relations. American Sociological Review 63(6): 871-894.

London T and Hart SL (2004) Reinventing strategies for emerging markets: Beyond the transnational model. Journal of International Business Studies 35(5): 350-370.

Longstaff FA (2010) The subprime credit crisis and contagion in financial markets. Journal of Financial Economics 97(3): 436-450.

Madhaven A and Cheng M (1997) In search of liquidity: Block trades in the upstairs and downstairs markets. The Review of Financial Studies 10(1): 175-203.

Macy MW, Kitts JA, Flache A and Benard S (2003) Polarization in dynamic networks: A Hopfield model of emergent structure. In: Breiger R, Carley K and Pattison PE (eds) Dynamic Social Network Modeling and Analysis. Washington, DC: The National Academic Press, pp.162-173.

May RM (1973) Stability and Complexity in Model Ecosystems. Princeton, NJ: Princeton University Press.

McCullough, ME, Kurzban R and Tabak BA (2010) Evolved mechanisms for revenge and forgiveness. In: Shaver PR and Mikulineer M (eds) Understanding and Reducing Aggression, Violence, and Their Consequences. Washington, DC, American Psychological Association, pp. 221-239.

Molm, LD (1997) Coercive Power in Social Exchange. New York, NY: Cambridge University Press.

Murnighan JK and Roth E (1983) Expecting continued play in prisoner's dilemma games: A test of several models. Journal of Conflict Resolution 27(2): 279-300. 


\section{The Market Dynamics of Socially Embedded Trading}

Oikarinen E (2010) Foreign ownership of stocks and long-run interdependence between national housing and stock markets - evidence from Finnish data. Journal of Real Estate Finance and Economics 41(4): 486-509.

Ostrom E (2004) Toward a behavioural theory linking trust, reciprocity, and reputation. In: Ostrom E and Walker J (eds) Trust and reciprocity: Interdisciplinary lessons from experimental research. New York, NY: Russell Sage Foundation, pp. 19-79.

Oxelheim L (2000) Routes to equity market integration - The interplay between politicians, investors and management. IUI Working Paper, No. 526. Stockholm, Sweden: Research Institute of Industrial Economics.

Padgett JF and Powell WW (2012) The Emergence of Organizations and Markets. Princeton, NJ: Princeton University Press.

Raudenbush SW (2009) Adaptive centering with random effects: An alternative to the fixed effects model for studying time-varying treatments in school settings. Journal of Education, Finance and Policy 4(4): 468-491.

Raudenbush SW and Bryk AS (2002) Hierarchical Linear Models: Applications and Data Analysis Methods, $2^{\text {nd }}$ edition. Advanced Quantitative Techniques in the Social Science Series, Vol. 1. Thousand Oaks, Cal.: Sage Publications.

Robins GL, Snijders TAB, Wang P, Handcock MS and Pattison, PE (2007) Recent developments in exponential random graph $\left(\mathrm{p}^{*}\right)$ models for social networks. Social Networks 29: 192215.

Schumann K and Ross M (2010) The benefits, costs, and paradox of revenge. Social and Personality Psychology Compass 4(12): 1193-1205.

Seppi DD (1990) Equilibrium block trading and asymmetric information. Journal of Finance 45(1): 75-94.

Simmel G and Wolff KH (1950) The Sociology of Georg Simmel. New York, NY: Simon and Schuster.

Snijders TAB, Pattison PE, Robins GL and Handcock MS (2006) New specifications for exponential random graph models. Sociological Methodology 36(1): 99-153.

Southall RJ (1978) Farmers, traders and brokers in the Gold Coast cocoa economy. Canadian Journal of African Studies 12(2): 185-211.

Verousis $\mathrm{T}$ and Gwilym $\mathrm{O}$ (2014). The implications of a price anchoring effect at the upstairs market of the London Stock Exchange. International Review of Financial Analysis 32: 37-46.

White HC (1981) Where do markets come from? Advances in Strategic Management 17(2): 323 350.

White HC (2002) Markets from Networks: Socioeconomic Models of Production. Princeton, NJ: Princeton University Press.Yoon, J., Thye, S.R. and Lawler, E.J., (2013). Exchange and cohesion in dyads and triads: A test of Simmel's hypothesis. Social Science Research, 42(6), pp.1457-1466. 
The Market Dynamics of Socially Embedded Trading

Table 1. Pay-offs in Prisoner's Dilemma between traders A and B

\begin{tabular}{|c|c|c|}
\hline & \multicolumn{2}{|c|}{ Trader B } \\
\hline Trader A & Defect & Cooperate \\
\hline Defect & 0,0 & $\alpha, \beta$ \\
\hline Cooperate & $\beta, \alpha$ & 1,1 \\
\hline
\end{tabular}

Table 2. Example of trading information for Nokia on the Helsinki Stock Exchange June 18, 


\begin{tabular}{|c|c|c|c|c|c|c|c|c|}
\hline Buyer & $\begin{array}{c}\text { Buyer } \\
\text { Firm }\end{array}$ & Seller & $\begin{array}{c}\text { Seller } \\
\text { Firm }\end{array}$ & $\begin{array}{c}\text { Trade } \\
\text { Date }\end{array}$ & $\begin{array}{c}\text { Trade } \\
\text { Time }\end{array}$ & $\begin{array}{c}\text { Stock } \\
\text { Ticker }\end{array}$ & $\begin{array}{c}\text { Share } \\
\text { Volume }\end{array}$ & $\begin{array}{c}\text { Trade } \\
\text { Price }\end{array}$ \\
\hline \hline 20 & 3 & 33 & 17 & 970618 & 124612 & NOKAV & 2000 & 36100 \\
\hline 20 & 3 & 56 & 17 & 970618 & 131727 & NOKAV & 2000 & 36110 \\
\hline 83 & 10 & 98 & 10 & 970618 & 141215 & NOKAV & 5000 & 36300 \\
\hline 83 & 10 & 98 & 10 & 970618 & 143305 & NOKAV & 2000 & 36350 \\
\hline 83 & 10 & 98 & 10 & 970618 & 144245 & NOKAV & 2000 & 36350 \\
\hline 83 & 10 & 98 & 10 & 970618 & 144444 & NOKAV & 1400 & 36350 \\
\hline 98 & 10 & 15 & 10 & 970618 & 151127 & NOKAV & 100 & 36300 \\
\hline 15 & 10 & 98 & 10 & 970618 & 155409 & NOKAV & 5000 & 36100 \\
\hline 83 & 10 & 98 & 10 & 970618 & 155709 & NOKAV & 700 & 36100 \\
\hline 83 & 10 & 98 & 10 & 970618 & 155950 & NOKAV & 1000 & 36050 \\
\hline 83 & 10 & 98 & 10 & 970618 & 164733 & NOKAV & 3000 & 36200 \\
\hline
\end{tabular}

Note: Buyers and sellers and their firms are denoted by numerical codes. Trade date is year (yy), month (mm), day (dd). Trade time is hour using a 24 hour clock $(\mathrm{hh})$, minute $(\mathrm{mm})$, and second $(\mathrm{ss})$. Share volume is number of shares traded at the trade price, which is measured in pennis. 


\section{The Market Dynamics of Socially Embedded Trading}

Table 3. Association between trading in one week and trading in the next week

\begin{tabular}{|c|c|c|}
\hline Trading $>1000$ & Trading $>1000$ Shares at Week $\mathrm{t}+1$ \\
\cline { 2 - 3 } Shares at Week t & No & Yes \\
\hline No & 660,460 & 1,207 \\
\hline Yes & 1,206 & 551 \\
\hline \multicolumn{2}{|c|}{ Odds Ratio $=250.00 ;$ p-value $<0.0001$} \\
\hline
\end{tabular}

Table 4. Association between consecutive weeks of trading and stock price deviation from mean stock price (VWAP averaged over the week)

\begin{tabular}{|l||l|}
\hline \multirow{2}{*}{} & Price Deviated from Mean Stock Price \\
\cline { 2 - 2 } & Coefficient (SE) \\
\hline \hline Intercept & $119.406(4.299)^{* * *}$ \\
\hline Consecutive Weeks of Trading & $5.802(0.701)^{* * *}$ \\
\hline
\end{tabular}

Note: ${ }^{* * *} \mathrm{p} \leq .0001$.

Standard Deviations of Consecutive Weeks of Trading and Price Deviated from Mean Stock Price are 5.037 and 323.734 respectively. Effect Size of Consecutive Weeks of Trading is 0.09 . 
Table 5. Descriptive statistics for variables used in model of interrupted trading partnership

\begin{tabular}{|l||c|c|}
\hline Variable & Mean & $\begin{array}{l}\text { Standard } \\
\text { Deviation }\end{array}$ \\
\hline Interruption of Partnership (2 weeks) & 0.09 & 0.29 \\
\hline Deviation in Price x Thousands Shares Traded & 353.58 & 202.13 \\
\hline Number of Asymmetric Third Parties & 10.94 & 2.77 \\
\hline Number of Common Third Parties & 3.97 & 2.52 \\
\hline Same Brokerage House Only & 0.08 & .27 \\
\hline Same Trading Clique Only & .07 & .26 \\
\hline Same Brokerage House and Same Trading Clique & .30 & .46 \\
\hline \# of Weeks of Continuous Trading & 1.54 & 3.43 \\
\hline Quarter 2 & 0.09 & 0.29 \\
\hline Quarter 3 & 0.12 & 0.33 \\
\hline Quarter 4 & 0.11 & 0.32 \\
\hline Quarter 5 & 0.14 & 0.35 \\
\hline Quarter 6 & 0.13 & 0.34 \\
\hline Quarter 7 & 0.19 & 0.39 \\
\hline Quarter 8 & 0.21 & 0.41 \\
\hline Sample Size & . & \\
\hline
\end{tabular}

Sample size $=760$ partnerships averaged across quarters, except for "interruption of partnership" which varies within quarter (sample size $=1293$ ). The data represent 87 traders; 19 traders did not form any partnerships we observed in our two years of data. 
Table 6. Multilevel linear probability regression of interrupted trading partnerships

\begin{tabular}{|l||l||l|}
\hline Predictor & \multicolumn{1}{|c|}{${\text { Model } 1^{\mathrm{a}}}^{-1} \begin{array}{c}\text { Model } 2^{\mathrm{a}} \text { (pair mean } \\
\text { centered) }\end{array}$} \\
\cline { 2 - 3 } & Coefficient $(\mathrm{SE})$ & Coefficient (SE) \\
\hline Intercept & $-0.104(0.038)$ & $0.053(0.013)$ \\
\hline Number of Asymmetric Third Parties & $-0.076(0.028)^{* *}$ & $0.133^{*}(0.054)$ \\
\hline Number of Common Third Parties & $0.012(0.003)^{* * *}$ & $-0.005(0.005)$ \\
\hline Same Brokerage House Only & $0.018(0.003)^{* * *}$ & $0.015(0.005)^{* * *}$ \\
\hline Same Trading Clique Only & $0.007(0.032)$ & $0.133(0.095)$ \\
\hline Same Brokerage House and Same Trading Clique & $.009(.034)$ & $-.025(.055)$ \\
\hline \# of Weeks of Continuous Trading through Previous Week & $.000042(.003)$ & $.171(.083)^{*}$ \\
\hline Number of partnerships & $1293(.021)^{* * *}$ & $.002(.003)$ \\
\hline Number of pairs & 760 & 516 \\
\hline Number of brokers & 87 & 360 \\
\hline
\end{tabular}

${ }^{a}$ Fixed effects for quarters not shown.

Note: ${ }^{*} \mathrm{p} \leq .05 ;{ }^{* *} \mathrm{p} \leq .01 ;{ }^{* * *} \mathrm{p} \leq .001$. 
The Market Dynamics of Socially Embedded Trading

\begin{tabular}{|c|c|c|}
\hline \multirow{5}{*}{$\begin{array}{l}\text { All pairs: } \\
116 \text { buyers } x \\
(116-1) \text { sellers }= \\
6670 \text { possible } \\
\text { dyads } x 8 \\
\text { quarters }=46690 \\
\text { possible pairs } \\
\text { across quarters. }\end{array}$} & & Yes \\
\hline & & \\
\hline & $\begin{array}{l}\text { Trading partnership } \\
\text { established } \\
\text { (trading more than } 1,000\end{array}$ & $\begin{array}{l}\text { tnership } \\
\text { rupted? }\end{array}$ \\
\hline & $\begin{array}{l}\text { For at least a two-week } \\
\text { interval). } \\
n=1,293\end{array}$ & $\begin{array}{c}\text { No } \\
n=1,173\end{array}$ \\
\hline & & \\
\hline
\end{tabular}

January 1996

December 1997

Figure 1. Status of trading partnerships 
The Market Dynamics of Socially Embedded Trading 


\section{The Market Dynamics of Socially Embedded Trading}

On-line Appendix A: Distribution of time of Interrupted trades

Figure A1 below shows that the frequency of stopped trading for at least two weeks drops dramatically from one week and then the frequencies decrease slowly while the weeks of stopped trading increase. If we define an interruption as suspended trading of at least one week then $43 \%$ of the partnerships would have had been interrupted, which seems highly volatile and possibly reflects incidental events (being ill, on vacation, or attending to personal matters) not related to deliberate choices. On the other hand if we define interruption in terms of suspended trading of three weeks or more then less than $4 \%$ (about 50) of the partnerships would have been interrupted, which may be too extreme an event to systematically model. Therefore we defined a partnership as interrupted if trading was suspended for two or more weeks. In our robustness checks we comment on models in which interruption is defined by a one week or three week interval. In our robustness checks we comment on models in which interruption is defined by a one week or three week interval (Appendix C). 
The Market Dynamics of Socially Embedded Trading

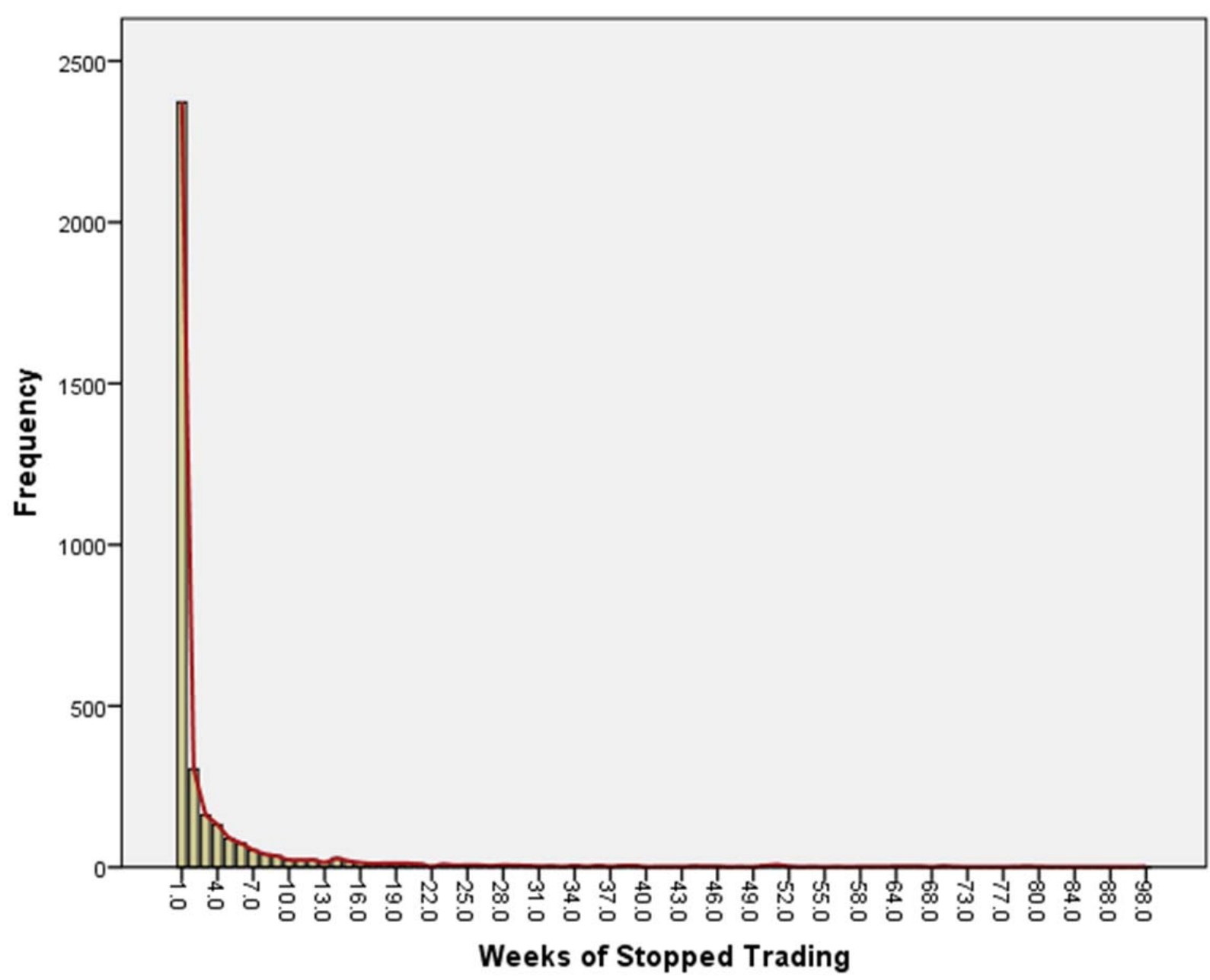

Figure A1. Frequencies of weeks of interrupted trading 
On-line Appendix B: Analysis of All Trades

Models 3 and 4 reported in Table A1 show results of our models when applied to all traded stocks. All inferences for our hypotheses from our main models are sustained (using a significance level of .05).

Table B1. Multilevel linear probability regression of interrupted trading partnerships

\begin{tabular}{|c|c|c|c|c|}
\hline Predictor & Model $1^{\mathrm{a}}$ & $\begin{array}{l}\text { Model } 2^{a} \text { (pair } \\
\text { mean centered) }\end{array}$ & $\begin{array}{c}\text { Model } 3 \\
\text { (all stocks and } \\
\text { all trades) }\end{array}$ & $\begin{array}{c}\text { Model } 4 \\
\text { (all trades and } \\
\text { stocks pair mean } \\
\text { centered) }\end{array}$ \\
\hline & Coefficient (SE) & Coefficient (SE) & Coefficient (SE) & Coefficient (SE) \\
\hline Intercept & $-0.104(0.038)$ & $0.053(0.013)$ & $-.148(.047)$ & $.051(.013)$ \\
\hline Deviation in Price $\mathrm{x}$ Thousands of Shares & $-0.076(0.028) * *$ & $0.133(0.054)^{*}$ & $-.079(.028)^{* *}$ & $.110(.054)^{*}$ \\
\hline Number of Asymmetric Third Parties & $0.012(0.003)^{* * *}$ & $-0.005(0.005)$ & $.009(.002) * * *$ & $.0007(.004)$ \\
\hline Number of Common Third Parties & $0.018(0.003)^{* * *}$ & $0.015(0.005)^{* * *}$ & $.012(.002) * * *$ & $.012(.004) * *$ \\
\hline Same Brokerage House Only & $0.007(0.032)$ & $0.133(0.095)$ & $.021(.027)$ & $.151(.080)$ \\
\hline Same Trading Clique Only & $.009(.034)$ & $-.025(.055)$ & $.012(.032)$ & $-.039(.049)$ \\
\hline Same Brokerage House and Same Trading Clique & $.123(.021)^{* * *}$ & $.171(.083)^{*}$ & $.106(.022) * * *$ & $.133(.074)$ \\
\hline $\begin{array}{l}\text { \# of Weeks of Continuous Trading through } \\
\text { Previous Week }\end{array}$ & $.000042(.003)$ & $.002(.003)$ & $-.000032(.0028)$ & $.00307(.0026)$ \\
\hline Number of partnerships & 1293 & 516 & 1488 & 793 \\
\hline Number of pairs & 760 & 360 & 930 & 435 \\
\hline Number of brokers & 87 & 87 & 91 & 91 \\
\hline
\end{tabular}

${ }^{a}$ Fixed effects for quarters not shown.

Note: ${ }^{*} \mathrm{p} \leq .05 ;{ }^{* *} \mathrm{p} \leq .01 ;{ }^{* * *} \mathrm{p} \leq .001$. 
On-line Appendix C: Analyses for Interruptions of One and Three Weeks

Table C1. Multilevel linear probability regression of interrupted trading partnerships for one week and three week interruptions (gaps)

\begin{tabular}{|c|c|c|c|c|c|c|}
\hline $\begin{array}{l}\text { Predictor } \\
\text { Coefficient (SE) }\end{array}$ & Model $1^{\mathrm{a}}$ & $\begin{array}{l}\text { Model 2 } \\
\text { (pair mean } \\
\text { centered) }\end{array}$ & $\begin{array}{l}\text { Model } 3^{\mathrm{a}} \\
1 \text { week gap }\end{array}$ & $\begin{array}{l}\text { Model } 4^{\mathrm{a}} \\
\text { 1 week gap } \\
\text { (pair mean } \\
\text { centered) }\end{array}$ & $\begin{array}{l}\text { Model } 5 \\
3 \text { week gap }\end{array}$ & $\begin{array}{c}\text { Model } 6 \\
3 \text { week gap } \\
\text { (pair mean } \\
\text { centered) }\end{array}$ \\
\hline Intercept & $-0.104(0.038)$ & $0.053(0.013)$ & $-.094(.067)$ & $.101(.028)$ & $-.054(.027)$ & $.033(.007)$ \\
\hline $\begin{array}{l}\text { Deviation in Price } \mathrm{x} \text { Thousands of Shares } \\
\text { Traded }\end{array}$ & $-0.076(0.028) * *$ & $0.133(0.054)^{*}$ & $-.020(.046)$ & $.010(.089)$ & $-.030(.019)$ & $.073^{*}(.037)$ \\
\hline Number of Asymmetric Third Parties & $0.012(0.003)^{* * *}$ & $-0.005(0.005)$ & $\begin{array}{l}.0089^{*} \\
(.0037)\end{array}$ & $-.010(.006)$ & $\begin{array}{l}.007^{* * *} \\
(.002)\end{array}$ & $-.005(.003)$ \\
\hline Number of Common Third Parties & $0.018(0.003)^{* * *}$ & $\begin{array}{l}0.015 * * * \\
(0.005)\end{array}$ & $.020^{* *}(.004)$ & $.012(.007)$ & $\begin{array}{l}.008^{* * *} \\
(.002)\end{array}$ & $\begin{array}{l}.012^{* * *} \\
(.003)\end{array}$ \\
\hline Same Brokerage House Only & $0.007(0.032)$ & $0.133(0.095)$ & $.115^{* *}(.039)$ & $.206(.122)$ & $-.002(.023)$ & $.144^{*}(.067)$ \\
\hline Same Trading Clique Only & $.009(.034)$ & $-.025(.055)$ & $.062(.040)$ & $.042(.067)$ & $.003(.025)$ & $-.052(.039)$ \\
\hline $\begin{array}{l}\text { Same Brokerage House and Same Trading } \\
\text { Clique }\end{array}$ & $.123(.021)^{* * *}$ & $.171(.083)^{*}$ & $\begin{array}{l}.498^{* * *} \\
(.030)\end{array}$ & $\begin{array}{l}.425^{* * *} \\
(.107)\end{array}$ & $\begin{array}{l}.052^{* * *} \\
(.014)\end{array}$ & $\begin{array}{l}.158^{* *} \\
(.058)\end{array}$ \\
\hline $\begin{array}{l}\text { \# of Weeks of Continuous Trading through } \\
\text { Previous Week }\end{array}$ & $.000042(.003)$ & $.002(.003)$ & $\begin{array}{l}.027^{* * *} \\
(.003)\end{array}$ & $.031(.003)$ & $-.002(.002)$ & $.001(.002)$ \\
\hline Number of partnerships & 1293 & 516 & 1293 & 1293 & 1293 & 1293 \\
\hline Number of pairs & 760 & 360 & 745 & 745 & 745 & 745 \\
\hline Number of brokers & 87 & 87 & 87 & 87 & 87 & 87 \\
\hline
\end{tabular}

${ }^{\mathrm{a}}$ Fixed effects for quarters not shown.

Note: ${ }^{*} \mathrm{p} \leq .05 ;^{* *} \mathrm{p} \leq .01 ;{ }^{* * *} \mathrm{p} \leq .001$. 


\section{The Market Dynamics of Socially Embedded Trading}

While some inferences are stronger than others, using $\mathrm{p}<.05$ most are consistent with some exceptions. In particular, the inferences for deviation in price $\mathrm{x}$ thousands of shares traded are not statistically significant in the 1 week interruption model (uncentered or centered) and for the 3 week interruption model uncentered. Inferences for asymmetric third parties are identical across all models. Inferences for common third parties are consistent except for the 1 week interruption model with pair mean centering ( $p=.073$ ). 


\section{The Market Dynamics of Socially Embedded Trading}

\section{Endnotes:}

'Formally, Kreps et al., use $\delta(0 \leq \delta \leq 1)$ to represent the probability that an actor plays a strategy other than the purely rational defection (e.g., Tit-for-Tat). They then show that "there is no finking [defecting] along the equilibrium path when more than $1+(2 \alpha-4 \beta+2 \delta) / \delta$ stages remain" to be played (page 250). Note that the larger the value of unilateral defecting $(\alpha)$ the greater the remaining stages and therefore the higher the value of defecting earlier in the game. Furthermore, the players wait past the first iteration as long as $\delta>\alpha-2 \beta$, and the larger $\delta$ relative to $\alpha-2 \beta$ the longer they wait to defect.

${ }^{i i}$ HEX has grown externally. In 1997 HEX purchased the two extant Finnish derivative exchanges. Moreover, after acquiring the Tallin and Riga stock exchanges in 2003, HEX merged with the owner of OMX, the owner of the Stockholm Stock Exchange. In 2008, the merged company, OMX HEX, was bought by NASDAQ and renamed NASDAQ OMX Helsinki. The nature of the upstairs market has remained basically the same despite the legal organizational changes.

iii We ignore after hours trades for two reasons. First, the prices at which these trades are executed are governed by the highest ask price and the lowest bid price occurring in the downstairs market in the previous downstairs trading session. Thus, the execution price is not freely determined in after-hours trading. Second, after hours trades often are a paper mechanism to transfer stocks acquired in multiple transactions by a broker for a client in the downstairs market to the client at the end of the day in a lump sum transaction. 


\section{The Market Dynamics of Socially Embedded Trading}

${ }^{\text {iv }}$ We originally estimated effects for different types of third parties (e.g., common sellers versus common buyers) but found the effects were similar and collinear when entered together, so we summed across all possible types.

${ }^{v}$ Network models contain unusual dependencies (see Snijders et al. 2006). In our analysis, the dependent "network" variable is whether an established partnership had been interrupted or not. Thus we model relationships in less than $3 \%$ of all possible pairs of traders $(1,293$ out of 46,690 possible pairs - see Figure 2). Furthermore the triadic relationships defining our key predictor are based on data from two different types of relations- a partnership relation defined by two weeks of consecutive trading versus the presence of another trader defined by trading in a single week. Given the level of missing data and the different definitions of relations, the statistical and substantive theories of standard network models (e.g., exponential random graph models) do not apply. Nevertheless, it is important to account for the tendency for traders to participate in interrupted partnerships as we do through the relational event framework.

${ }^{v i}$ Even in this case, however, one could make the argument that the presence of third parties is causal, but mediated by friendships. Indeed, De Quillacq (1992) reports that an actor who engaged as a third party in hostile transactions among highly competitive French bankers lost several key friendships and the core of his entire friendship circle.

vii Even though prices are constrained by the downstairs market, there is apparently considerable leeway for traders to execute trades between the bid/ask prices in the downstairs market (especially when applied to the larger orders of the upstairs market). 